\title{
Dependencies between Pre-existing and Newly Obtained Knowledge
}

\author{
Sylvia Encheva ${ }^{1 *}$ \\ ${ }^{1}$ Stord/Haugesund University College, Bjørnsonsg. 45, 5528 Haugesund, Norway \\ ${ }^{*}$ Corresponding author
}

\begin{abstract}
Computation skills in mathematics play an essential role in developing students' abilities to handle procedurally oriented tasks. Reasoning on the other hand, being a higher-order cognitive ability, supports recognition of patterns and relationships. Finding correlations between students' performance results over a period of time can provide important inside explanations about what makes part of the learners to actively use previously obtained knowledge in their future studies while others merely possess it.
\end{abstract}

Keywords-event sequences; frequent patterns; mathematical competancies

\section{INTRODUCTION}

Higher order cognitive abilities are indispensable when it comes to learning new mathematical concepts on graduate level A nonexhaustive list including cognitive factors, metacognitive factors, habits of learning and previous experiences related to studying mathematics is presented in [5]. It is pointed out in [6] that if students are unable to understand a difficult mathematics class because it is at a level above their ability to respond to the instruction, the students may not progress to the affective level of valuing the instruction. Students mathematical competencies are also discussed in [9]. A number of problems related to building mathematical concepts are listed in [1].

Suppose students have to take several consequtive mathematics courses where each course is a prerequisite for taking the next one. A question we try to answer here is whether there are some patterns relating students results historically. Methods from the theory of directed graphs and episodes from events sequences are employed for bringing out frequent patterns in students performance.

The rest of the paper goes as follows. Theoretical supporting the study is presented in Section 2, our approach can be found in Section 3 while the conclusion is placed in Section 4

\section{PRELIMINARIES}

Below presented theory related to episodes in event sequences follows [7]. Given a set $E$ of event types, an event is a pair $(A, t)$, where $A \in E$ is an event type and $t$ is an integer, the (occurrence) time of the event.
An event sequence $S$ on $E$ is a triple $\left(s, T_{s}, T_{e}\right)$, where $s=\left(A_{1}, t_{1}\right),\left(A_{2}, t_{2}\right), \ldots,\left(A_{n}, t_{n}\right)$

is an ordered sequence of events such that $A_{i} \in E$ for all $i=1, \ldots, n$, and $t_{i} \leq t_{i+1}$ for all $i=1, \ldots, n$. Further on, $T_{s}$ and $T_{e}$ are integers: $T_{s}$ is called the starting time and $T_{e}$ the ending time, and $T_{s} \leq t_{i}<T_{e}$ for all $i=1, \ldots, n$.

An episode $\alpha$ is a triple $(V, \leq, g)$ where $V$ is a set of nodes, $\leq$ is a partial order on $V$, and $g: V \rightarrow E$ is a mapping associating each node with an event type. The interpretation of an episode is that the events in $g(V)$ have to occur in the order described by $\leq$. The size of $\alpha$, denoted $|\alpha|$, is $|V|$. Episode $\alpha$ is parallel if the partial order $\leq$ is trivial (i.e., $x \not \leq y$ for all $x, y \in V$ such that $x \neq y$ ). Episode $\alpha$ is serial if the relation $\leq$ is a total order (i.e., $x \leq y$ or $y \leq x$ for all $x, y \in V$ ). Episode $\alpha$ is injective if the mapping $g$ is an injection, i.e., no event type occurs twice in the episode.

A lattice is a partially ordered set, closed under least upper and greatest lower bounds. The least upper bound of $x$ and $y$ is called the join of $x$ and $y$, and is sometimes written as $x+y$; the greatest lower bound is called the meet, [3], [2], and [4]. A partially ordered set in which all pairs have a meet is meet-semilattice, [3].

\section{EFFECT OF PREVIOUSLY TAKeN COURSES ON OBTAINING NEW KNOWLEDGE}

This study $i$ data describing students results in mathematics courses on graduate level. We adopt the following devision of students with respect to obtained amount of knowledge, skills and understanding in a course: if their final grade is A, B, C, or $\mathrm{D}$ then we call it satisfactory, if their final grade is $\mathrm{E}$ then is somewhat unclear, and if it is F, i.e. they fail then it is obviously unsatisfactory.

Quite often educators spend most of their efforts to support students who might be in danger of not been able to pass their exams and even drop out. As a consequence the rest of the students receive less attention due to limited amount of resources in high education. In this work we apply data mining 
techniques for extracting frequent episodes from students results in order to find out whether previous knowledge play a significant role in obtaining new knowledge.

Students been subjects of this study have to take three consecutive mathematics courses.

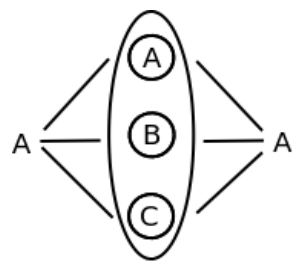

FIGURE I.

\section{SERIAL EPISODE WITH INITIAL GRADE A AND FINAL GRADE A}

Students with final grade $\mathrm{A}$ in the third course: In about $90 \%$ of the cases where students receive $\mathrm{A}$ in the third course there is at least one A among their grades in the previous courses. Exceptions however are possible. The most frequent serial episodes are shown in Figure 1, Figure 2, and Figure 3. The left side letter in each graph shows students final grades in the first course, letters in the middle refer to students final grades in the second course, while the right side letter shows students final grades in the third course.

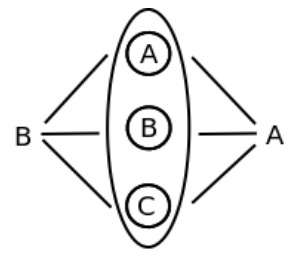

FIGURE II.

$$
\begin{aligned}
& \text { SERIAL EPISODE WITH INITIAL GRADE B AND } \\
& \text { FINAL GRADE A }
\end{aligned}
$$

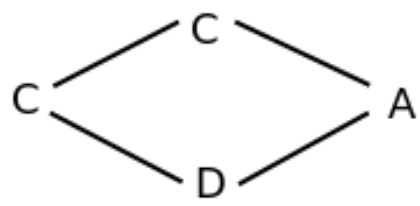

FIGURE III.

\section{SERIAL EPISODE WITH INITIAL GRADE C AND} FINAL GRADE A

Students with final grade B in the third course: Final grade $\mathrm{B}$ in the third course implies at least one B or C among their grades in the previous courses. Exceptions are again possible. The most frequent serial episodes are shown in Figure 4, and Figigure 5.

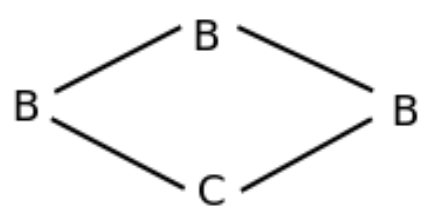

FIGURE IV

SERIAL EPISODE WITH INITIAL GRADE B AND FINAL GRADE B

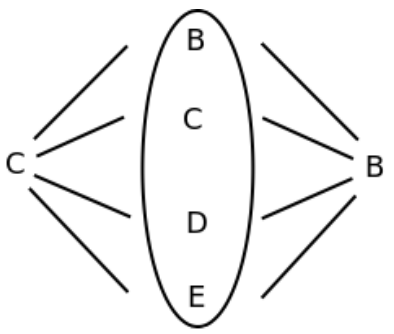

FIGURE V.

SERIAL EPISODE WITH INITIAL GRADE C AND FINAL GRADE B

Students with final grade $\mathrm{C}$ in the third course: About $75 \%$ of the students with final grade $\mathrm{C}$ in the third course had grade $\mathrm{C}$ twice in the previous courses and about $20 \%$ of the students with final grade $\mathrm{C}$ in the third course had at least one grade D earlier. The group of students with final grade $\mathrm{C}$ seems to be the most stable when it comes to variation of previous exam grades. The most frequent serial episodes are shown in Figure 6 and Figure 7.

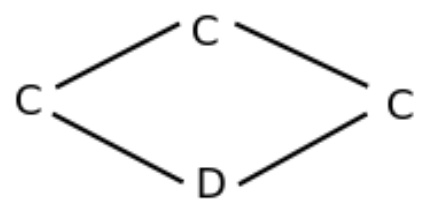

FIGURE VI

SERIAL EPISODE WITH INITIAL GRADE C AND FINAL GRADE C

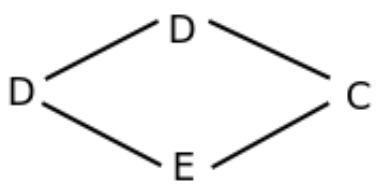

FIGURE VII.

SERIAL EPISODE WITH INITIAL GRADE D AND FINAL GRADE C

Students with final grade D in the third course: With some exceptions a final grade D in the third course implies at least one D or higher among their grades in the previous courses. The most frequent serial episodes are shown in Figure 8, Figure 9, and Figure 10.

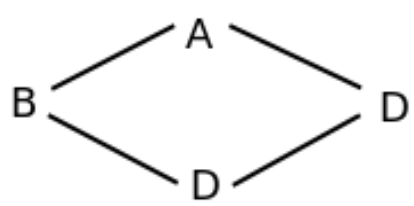

FIGURE VIII.

SERIAL EPISODE WITH INITIAL GRADE B AND FINAL GRADE C

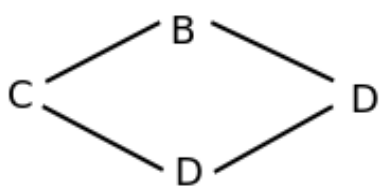

FIGURE IX. FINAL GRADE D 


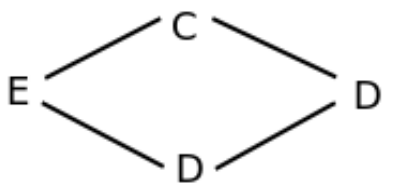

FIGURE X.

SERIAL EPISODE WITH INITIAL GRADE E AND FINAL GRADE D

Students with final grade $\mathrm{E}$ in the third course: The serial episodes for students with final grade $\mathrm{E}$ are quite similar to the ones with final grade D. A final $\mathrm{E}$ implies at least one $\mathrm{D}$ or $\mathrm{C}$ in previous courses.

Students with final grade $\mathrm{F}$ in the third course: The serial episodes for students with final grade $\mathrm{F}$ are quite similar to the ones with final grades $\mathrm{D}$ and $\mathrm{E}$. While a grade $\mathrm{F}$ in previous courses implies $\mathrm{F}$ in the final course more or less without exceptions, grades $\mathrm{C}$ or $\mathrm{D}$ in previous courses do not guarantee 'pass' for the final course.

Mining of diamond episodes can be further pursued by building pattern structure lattices as in [8]. Meet semi-lattices have been also used in [8] for building pattern structures.

\section{CONCLUSION}

Students prior mathematical knowledge are of utmost importance when it comes to building of higher order mathematical understanding. Keeping in mind the limitations of this study we would like to point out that a positive development in students' knowledge and skills (assuming higher grades correspond to larger amount of knowledge and skills) appears to be carried out between at most two consecutve courses. Therefore, even though students perform reasonably well at the beginning of their studies they should be strongly encouraged to put more efforts into it since it will definitely help them in pursuing their future education.

\section{REFERENCES}

[1] M. Berger, "Making mathematical meaning: from preconcepts to pseudoconcepts to concepts", Pythagoras, vol. 63, pp. 14-21, 2006.

[2] C. Carpineto and G. Romano, Concept Data Analysis: Theory and Applications. John Wiley and Sons, Ltd., 2004.

[3] B. A. Davey and H. A. Priestley, Introduction to lattices and order. Cambridge University Press, Cambridge, 2005.

[4] B. Ganter and R. Wille, Formal Concept Analysis, Springer, 1999.

[5] S. P. Gurganus, Characteristics of Students' Mathematics Learning Problems, http://www.education.com/reference/article/students-mathlearning-problems/

[6] S. D. LeMire, M. L. Melby, A. M. Haskins, and T. Williams, "The Devalued Student: Misalignment of Current Mathematics Knowledge and Level of Instruction," The Mathematics Educator, vol. 22, pp. 6383, 2012.

[7] H. Mannila, H. Toivonen, and A.Verkamo, “ Discovery of frequent episodes in event sequences," Data Mining and Knowledge Discovery vol. 1(3), pp. 259-289, 1997.

[8] K. Otaki, M. Ikeda, A. Yamamoto, "Pattern Structures for Understanding Episode Patterns", CLA 2014, pp. 47-58, 2014.

[9] R. Turner, Exploring mathematical competencies, Research Developments, vol. 24, no. 5, 2011. 